\title{
FACTORS ASSOCIATED WITH THE KNOWLEDGE, PRACTICE AND PERCEPTIONS OF CONTRACEPTION IN RURAL SOUTHERN NIGERIA
}

\author{
L. O. OMO-AGHOJA ${ }^{1}$, V. W. OMO-AGHOJA ${ }^{2}$, C. O. AGHOJA ${ }^{3}$, F. E. OKONOFUA ${ }^{4}$, O. \\ AGHEDO $^{5}$, C. UMUERI $^{6}$, R. OTAYOHWO ${ }^{7}$, P. FEYI-WABOSO $^{8}$, E. A. ONOWHAKPOR ${ }^{1}$ and \\ K. A. INIKORI
}

${ }^{1}$ Department of Obstetrics and Gynaecology, College of Health Sciences, Delta State University, Abraka, Nigeria; ${ }^{2}$ Department of Oral and Maxillofacial Surgery, University of Benin Teaching Hospital, Benin City,

${ }^{3}$ Department of Clinical Pharmacy, Faculty of Pharmacy, Delta State University, Abraka, Nigeria;

${ }^{4}$ Department of Obstetrics and Gynaecology, College of Medical Sciences, University of Benin, Benin City, Nigeria; ${ }^{5}$ SERAC, Lagos, ${ }^{6}$ Central Hospital, Sapele, Nigeria; ${ }^{7}$ State School of Midwifery, Amukpe, Nigeria; ${ }^{8}$ Department of Obstetrics and Gynaecology, Abia State University Teaching Hospital, Aba, Nigeria and Department of Radiology, College of Health Sciences, Delta State University, Abraka, Nigeria.

Corresponding Author: Dr. Lawrence Omo-Aghoja

Conflict of interest: None declared

\section{SUMMARY}

Background: Significant proportion of maternal deaths in Nigeria is due to complications of unsafe abortions, and these abortions are responses to unwanted pregnancies that could have been prevented by effective contraceptive programming. Despite intense programmatic efforts by the Nigerian government and various non-governmental agencies to reverse the trend, there has been little evidence to suggest a systematic improvement in these indicators.

Methodology: A household random survey of 1,528 women aged between 15-49 years was undertaken at Amukpe community in Nigeria, to determine their knowledge, practice and perceptions of contraception. Results: The results showed that $86.2 \%$ of the respondents had secondary or less level of education and $19.2 \%$ of the respondents were single parents. The level of contraceptive awareness was high (92.3\%) and $88 \%$ of the respondents became aware of contraception in the last 14 years. Friends/relatives $(40.6 \%)$, followed by nurses $(31.7 \%)$ and then doctors $(17.3 \%)$ were the common sources of contraceptive awareness. The most widely known contraceptive methods were injectables, condoms, POP and OCP. The specific knowledge of emergency contraception was poor. The factors associated with low contraceptive usage were poor level of training and ineffective conveyance of relevant information to clients by health personnel, low literacy levels, extremes of reproductive age and extremes of parity. Others were fear of side effects, lack of knowledge, and lack of spousal consent.

Conclusion: Contraceptive usage remain poor despite high level of awareness. Effective educational and counseling interventions are likely to improve provid-

\section{E mail: eguono 2000@yahoo.com, losuakpor@gmail.com}

ers' and consumers' knowledge and subsequent uptake of contraceptive usage.

Key Words: Knowledge, practice and perceptions of contraception, rural southern Nigeria.

\section{INTRODUCTION}

Available data indicates that Nigeria currently has one of the highest rates of maternal mortality in the world. ${ }^{1}$ It is also in evidence that $40 \%$ of these maternal deaths are due to complications of unsafe abortions ${ }^{2}$, and abortion is a response to an unwanted pregnancy that could have been prevented by effective contraceptive programming. Yet Nigeria's contraceptive prevalence rate is less than $13 \%$. The situation is further compounded by the persisting challenge of high fertility rate of about $5.8 \%$ and an annual growth rate of $2.8 \%$ in face of a large population size of about 140 million persons. ${ }^{3}$ Despite intense programmatic efforts by the Nigerian government and various non-governmental agencies to reverse the trend, there has been little evidence to suggest a systematic improvement in these indicators. Primary prevention, based on reducing the numbers of at-risk pregnancies through effective contraception, is an important approach to resolving the problem.

However, to date contraception has not been well consolidated in Nigeria, with evidence from recent DHS data indicating that only about 13 percent of sexually active Nigerian women currently practice effective contraception. ${ }^{4}$ Part of the reasons for the poor use of contraception in Nigeria, include the persisting pronatalist culture of the people, religious preachments 
which discourage the use of contraception, poor availability and distribution of contraceptives and women's fear of contraceptive side effects. ${ }^{5,6}$ In particular, the perception that contraception could lead to infertility in later life is one reason that Nigerian women have always proffered for not accepting effective contraception. $^{7}$

Studies in Nigeria have reported that by the very way contraception is perceived, community involvement and participation is the gold standard to the initiation of an effective debate towards acceptance as seen with programmes aimed at reducing maternal mortality. This is further buttressed by the fact that community practices and cultural beliefs play significant roles in decision making vital to women's reproductive health. For instance, certain aspects of our culture strongly discourage modern contraceptive usage. There is the belief that women who use modern family planning method cut short the number of children God has in stock for them and as such may be punished with infertility on re-incarnation.

Therefore, as part of efforts to design measures to improve women's access to family planning services and post-abortion care in Amukpe community of Sapele local government area of Delta State of Nigeria under the auspices of an initiative supported by the Macarthur Foundation, a needs assessment survey was conducted to determine the factors associated with the knowledge, practice and perceptions of contraception in a typical rural Nigeria community. The findings of the needs assessment helped in designing relevant and culturally appropriate interventions that has aided the efforts at promoting and disseminating information on contraception to the eligible individuals and couples of this under-served community for the prevention of atrisk pregnancy in Nigeria.

We believe that the presentation of the needs assessment survey in this paper is capable of stimulating interest in replicating this work in other similar underserved community with the prospect of engendering more effective contraceptive programming.

\section{METHODS}

The study was conducted at Amukpe (an Okpe community in Sapele Local Government Area) in Delta Central Senatorial district of Delta State in the NigerDelta region of Nigeria. The study took place between December 2005 and July 2006 with support from the Macarthur Foundation. The settlement is rural with a few semi-urban enclaves, and has a population of nearly 71,356 people based on the 2002 National Population Commission census figures, with female population being 31,206.
Women of reproductive age group (15-49 years) including adolescents comprise $60 \%$ of the female population. The only available government health facility is a comprehensive health center that is ill equipped and understaffed. Additionally, there are two other private clinics that rarely render family planning and safe abortion services. The main occupation here consists of factory work, fishing, hunting, subsistence farming and trading as well as low cadre civil service. Also, there is active commercial sex activity going on in the community.

The unit of social organization is the family, which is patrilineal and patriarchal. The man is the head of the family and its breadwinner, while the woman is the procreator and housekeeper. Group of families who claim same ancestral descent or origin forms a kindred (or $\underline{k} k w a$ ) and many kindreds form the village (or okoh). The Amukpe community is made up of fifteen okohs and the community is overseen by a community development Association made up of male representatives of the 15 villages from amongst whom an executive committee is elected. The Community Development Association is answerable to the paramount ruler of the Okpe Kingdom (the Orodje of Okpe) whose palace is located at Orerokpe, the administrative headquarters of the Okpe people to which the Amukpe community belongs. Other associations in the community include the women leaders group, the youth association and associations of the various trade groups. The opinion of the community development association supersedes every other group and final on community issues that arises from time to time, except in cases of appeals against any decision that are referred to the Orodje. Members of the community development association act as the gatekeepers to the community and they must grant permission for entrance into the community for any study of this nature. Local tradition and culture typical of the Okpe people dominates the reproductive practices in the study community.

\section{The Needs Assessment Survey}

This consisted of a household random survey of 1,528 women aged between 15-49 years to determine their knowledge, practice and perceptions of contraception. The sample size for the study was calculated based on the population of the community of 71,356 people gotten from the figures of the 1991 population census with the females consisting 31,206 of this total figure. Women of reproductive age group comprised $60 \%$ of the female population giving an actual figure of 19,000. However, based on work done in other communities, we assume a $50 \%$ positive response rate on answers relating to abortion and family planning. The worst accepted positive response rate was pegged at 47.55 and a $95 \%$ confidence interval was assumed. 
This information was fed into Epi-info version 3.2.2 computer statistical package giving a sample size of 1,422 . But a convenient sample of 1,528 was collected using a detailed questionnaire.

The questionnaire was in four sections. In the first part of the questionnaire, we solicited information on the socio-demographic characteristics of the respondents age, education, marital status, religion and parity. In the second part of the questionnaire, we asked questions on the respondent's knowledge of contraception. In section 3 of the questionnaire, questions that sought to assess the respondent's practice of contraception were asked. In the final section of the questionnaire, we asked the women questions that tested the perceptions of the women to contraception.

This study was preceded by a qualitative study using focus group discussions and in-depth interviews to assess the views and perceptions of relevant rural community stakeholders in Amukpe community relating to contraception, unwanted pregnancy and unsafe abortion. As we believed that such information will be useful for identifying relevant and culturally appropriate interventions for resolving the problem of unsafe abortion and increased uptake of contraceptive usage. And one of the cardinal findings of that study was that the level of training in contraceptive services and how effectively health workers were able to convey relevant information to their clients was poor. The paper from this study titled: "Perceptions and attitudes of a rural community to abortion in the Niger-Delta region of Nigeria" has been accepted for publication by the $\mathrm{Ni}$ geria Journal of Clinical Practice and it is in press. ${ }^{10}$ Training and strengthening of the capacity of the health personnel in this community to render effective contraceptive services was undertaken following the study.

\section{Sampling}

The National Population Commission listing of household was used to obtain a stratified simple random sample for the household survey. All houses in Amukpe had been assigned a unique identification number under this scheme. The sampling was done at three levels. In level one, 19 streets were randomly selected from the known 55 streets and settlements in the area. In the second level sampling, each household within the selected streets were visited and identified to ensure that people were still leaving there. Fifteen households were then randomly selected from the 19 streets, making a total of 285 household overall. In each household about 5-10 women of reproductive age were interviewed.

The questionnaires were administered by trained young ladies aged between 15-25 years on eligible women in their homes after it had been pre-tested and validated amongst women in the community. We believe that asking women to interview women increased the internal validity of the responses. The interviewers approached the household in a very sensitive manner and obtained permission from the heads of the household to conduct the interviews. They then proceeded to identifying the eligible women within the household and sought their permission to be interviewed. Only those women who gave consent were interviewed. They were interviewed in privacy and assured of confidentiality of information provided.

Ethical clearance for this study was obtained from the Research and Ethics Committee of the College of Medical Sciences of the Delta State University, Abraka.

\section{Data management}

Data from the survey were entered into a computer database using the EPI-Info 2000 Software. They were then transformed from EPI-info into the more robust statistical software of SPSS PC+ and further analysis was conducted. The data were analyzed using univariate and bivariate statistics were appropriate. Tests of significance was based on $95 \%$ confidence interval $(p<0.05)$ using the chi square test with Yates and Fischer exact correction where applicable.

\section{RESULTS}

A total of 1528 respondents completed the questionnaire satisfactorily. The sociodemographic data are presented in Table 1. Their mean age was 28.76 (range $=15-49)$ years. Majority $(53.1 \%)$ of the respondents had secondary level of education and this was followed by primary level of education in about a third $(26.6 \%)$ of the studied population. About two thirds $(57.3 \%)$ of the respondents were single. $1446(94.8 \%)$ respondents were Christians and they were mostly $(52.3 \%)$ of the pentecostal denomination. The mean parity was 2.12 with a range of $0-15$. Six hundred and fifty $(42.7 \%)$ of the respondents had ever gotten married even if divorced, whereas 939 (61.9\%) had delivered previously. This implies that $289(19.2 \%)$ of the women interviewed in this community had children without being married (unplanned pregnancy).

The level of contraceptive awareness was high amongst the respondents as $1411(92.3 \%)$ of them had previously heard about contraception (Table 1). Majority $(88 \%)$ of the respondents became aware of contraception in the last 14 years with $43.9 \%$ within the immediate past 5 years.

Friends/relatives $(40.6 \%)$, followed by nurses $(31.7 \%)$ and then doctors $(17.3 \%)$ largely accounted for the sources of awareness of contraception. 
Table 1 Socio-demographic profile of respondents

\begin{tabular}{|c|c|c|}
\hline PARAMETER & FREQUENCY & $\%$ \\
\hline $\begin{array}{l}\text { A. AGE GROUP } \\
15-19 \\
20-24 \\
25-29 \\
30-34 \\
35-39 \\
40-44 \\
\geq 45 \\
\text { Mean age was 28.78 } \\
\text { (Range=15-49) years }\end{array}$ & $\begin{array}{l}261 \\
304 \\
289 \\
240 \\
216 \\
140 \\
77\end{array}$ & $\begin{array}{l}17.1 \\
19.9 \\
18.9 \\
15.7 \\
14.1 \\
9.2 \\
5.0\end{array}$ \\
\hline $\begin{array}{l}\text { B. EDUCATIONAL } \\
\text { STATUS } \\
\text { None } \\
\text { Primary } \\
\text { Secondary } \\
\text { Tertiary }\end{array}$ & $\begin{array}{l}100 \\
406 \\
811 \\
211\end{array}$ & $\begin{array}{l}6.5 \\
26.6 \\
53.1 \\
13.8 \\
\end{array}$ \\
\hline $\begin{array}{l}\text { C. MARITAL } \\
\text { STATUS } \\
\text { Single } \\
\text { Married } \\
\text { Divorced } \\
\text { Married but living apart }\end{array}$ & $\begin{array}{l}586 \\
876 \\
29 \\
37 \\
\end{array}$ & $\begin{array}{l}38.4 \\
12.6 \\
29.9 \\
0.5\end{array}$ \\
\hline $\begin{array}{l}\text { D. RELIGIOUS } \\
\text { STATUS } \\
\text { None } \\
\text { Catholic } \\
\text { Protestant } \\
\text { Muslim } \\
\text { Pentecostal } \\
\text { Traditional religion } \\
\end{array}$ & $\begin{array}{l}58 \\
192 \\
456 \\
7 \\
798 \\
16\end{array}$ & $\begin{array}{l}3.8 \\
12.6 \\
29.9 \\
0.5 \\
52.3 \\
1.0\end{array}$ \\
\hline $\begin{array}{l}\text { E. PARITY } \\
\text { None } \\
1-4 \\
5-9 \\
\geq 10 \\
\text { Mean parity was } 2.12 \\
\text { (range }=0.15)\end{array}$ & $\begin{array}{l}583 \\
686 \\
246 \\
13\end{array}$ & $\begin{array}{l}38.2 \\
44.9 \\
16.1 \\
0.9\end{array}$ \\
\hline TOTAL & 1528 & 100 \\
\hline
\end{tabular}

The media (print and electronic) on the other hand contributed only $10 \%$ of awareness. The most widely known contraceptives were injectables $(59.5 \%)$, condoms (42.2\%), POP (39.2\%) and OCP (34.0\%).

Above $60 \%$ of the sampled population did not know what emergency contraception is. While of the 600 (39.4\%) respondents that knew the definition of emergency contraception, $500(83.3 \%)$ knew the appropriate contraceptive methods that could be used for emergency contraception.
Table 2 Knowledge of contraception

\begin{tabular}{|c|c|c|}
\hline PARAMETER & FREQUENCY & $\%$ \\
\hline $\begin{array}{l}\text { A. AWARENESS } \\
\text { Yes } \\
\text { No } \\
\text { Not stated }\end{array}$ & $\begin{array}{l}1411 \\
115 \\
2\end{array}$ & $\begin{array}{l}92.3 \\
7.5 \\
0.1\end{array}$ \\
\hline $\begin{array}{l}\text { B. DURATION OF } \\
\text { AWARENESS } \\
\leq 5(\mathrm{yrs}) \\
6-10 \\
11-14 \\
15-19 \\
20-24 \\
\geq 25 \\
\text { Not aware } \\
\text { Not stated }\end{array}$ & $\begin{array}{l}620 \\
527 \\
181 \\
53 \\
111 \\
7 \\
126 \\
3\end{array}$ & $\begin{array}{l}43.6 \\
37.3 \\
12.8 \\
3.8 \\
0.8 \\
0.5 \\
8.9 \\
0.2\end{array}$ \\
\hline $\begin{array}{l}\text { C. SOURCES OF } \\
\text { AWARENES } \\
\text { Nurses } \\
\text { Doctors } \\
\text { Relatives/Friends } \\
\text { Chemists } \\
\text { Radio } \\
\text { Television } \\
\text { Newspaper } \\
\text { Other }\end{array}$ & $\begin{array}{l}439 \\
240 \\
562 \\
17 \\
50 \\
89 \\
10 \\
19\end{array}$ & $\begin{array}{l}31.7 \\
17.3 \\
40.6 \\
1.2 \\
3.6 \\
6.4 \\
0.7\end{array}$ \\
\hline $\begin{array}{l}\text { D. FAMILY PLAN- } \\
\text { NING METHOD } \\
\text { KNOWN } \\
\text { Abstinence } \\
\text { Coitus interruptus } \\
\text { OCP } \\
\text { POP } \\
\text { Injectables } \\
\text { Condoms } \\
\text { Norplant } \\
\text { IUCD } \\
\text { Others }\end{array}$ & $\begin{array}{l}92 \\
154 \\
480 \\
553 \\
840 \\
595 \\
30 \\
185 \\
100\end{array}$ & $\begin{array}{l}6.5 \\
10.9 \\
34.0 \\
39.2 \\
59.5 \\
42.2 \\
2.1 \\
13.5 \\
7.1\end{array}$ \\
\hline $\begin{array}{l}\text { E. EMERGENCY } \\
\text { CONTRACEPTION } \\
\text { Correct option } \\
\text { Wrong option } \\
\text { Don't know } \\
\text { Not stated } \\
\end{array}$ & $\begin{array}{l}600 \\
327 \\
596 \\
5\end{array}$ & $\begin{array}{l}39.4 \\
21.4 \\
39.1 \\
0.3\end{array}$ \\
\hline $\begin{array}{l}\text { F. WHO SHOULD } \\
\text { USE CONTRACEP- } \\
\text { TION } \\
\text { Correct option } \\
\text { Wrong option } \\
\text { Don't know } \\
\text { Not stated }\end{array}$ & $\begin{array}{l}747 \\
647 \\
129 \\
5\end{array}$ & $\begin{array}{l}48.9 \\
42.3 \\
8.4 \\
0.3\end{array}$ \\
\hline
\end{tabular}


On the other hand, 100 women had no clue as to what can be used. 747 (49\%) respondents knew what categories of women who should use contraception while 776 (50.7\%) respondents either did not know who should use contraception or had incomplete knowledge of this (Table 2).

Among the study population, 1319 (86.3\%) said they knew how to prevent unwanted pregnancy, while 209 $(13.7 \%)$ of the respondents had no knowledge of how to prevent an unwanted pregnancy. The commonly known methods of preventing unwanted pregnancy include the use of Injectables (49.7\%), pills $(45.0 \%)$ and condoms (37.7\%) (Table 3$)$.

Table 3 Knowledge of prevention of unwanted pregnancy

\begin{tabular}{|l|c|c|}
\hline PARAMETER & FREQUENCY & $\%$ \\
\hline A. PREVENTION OF & & \\
UNWANTED PREG. & & \\
Knows & 1319 & 86.3 \\
Does not know & 209 & 13.7 \\
\hline B. METHODS & & \\
KNOWN & 24 & \\
Foaming tablets & 656 & 4.8 \\
Injectables & 498 & 37.7 \\
Condoms & 593 & 45.0 \\
Pills & 178 & 13.5 \\
IUCD & 11 & 0.8 \\
Norplant & 2 & 0.2 \\
BTL & 189 & 14.3 \\
NFP & 129 & 9.3 \\
*others & & \\
*Menstrogen, Quinine, & Traditional Medication, \\
Gin/Alcoholic Beverages, Ampiclox/Ampiclox, Soda Water, \\
Krest, Becodeine, Gynaecosid, Ergot,7up, Chloroquin, Ala- \\
bukun Powder, Andrew's Salt.
\end{tabular}

Some respondents had used more than one method previously. Over half $(53.1 \%)$ of the respondents had never used contraception previously and the leading reasons why a larger proportion of respondents have never used contraceptives were fear of side effects $(33.5 \%)$, lack of knowledge (21.7\%) and lack of spousal consent (15.7\%).

Cultural, moral and religious reasons ranked low amongst the respondents (Table 4). For those that had ever used contraceptives, the pills $((51.3 \%)$, condoms $(27.4 \%)$ and the injectables $(19.4 \%)$ were the most widely ever used contraceptive methods (Table 4).

The contraceptive prevalence rate (current use) was $29 \%$, and $71 \%$ of respondents were not using any method of contraception.

Table 4 Practice of contraception

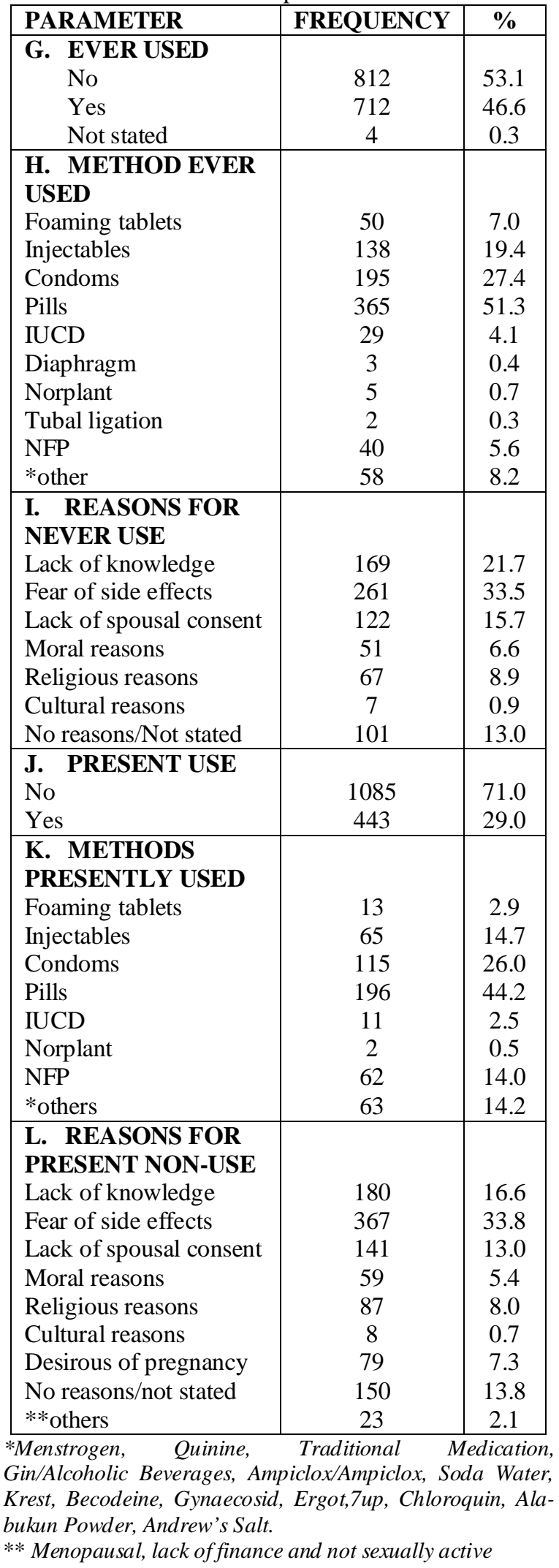


For those that were presently using contraception, the pills $(44.2 \%)$, condoms $(26.0 \%)$ and injectables $(14.7 \%)$ were the most widely used contraceptive methods. The fear of side effects $(33.8 \%)$, lack of knowledge (16.6\%) and lack of spousal consent $(13.0 \%)$ were the leading reasons for present non-use of contraceptives (Table 4).

Cross tabulation of the socio-demographic profiles of the respondents with the risk of having an unwanted pregnancy, use of contraception and not using contraception was done (not shown), and subjected to statistical analysis. It was clearly shown that the rate of unwanted pregnancy and contraceptive prevalence rate was not statistically significantly different in the single and married respondents.

The educational status significantly affected the occurrence of unwanted pregnancy and the contraceptive prevalence rate, with the respondents with secondary and less level of education more likely to have an unwanted pregnancy and also less likely to be using contraception as compared to those who attained tertiary level of education. The extremes of reproductive age accounted for higher rates of unwanted pregnancy and low contraceptive usage, and similarly extremes of parity were statistically significantly correlated with the risks of having unwanted pregnancy and low contraceptive prevalence rate with $\mathrm{p}$-values $<0.05$. Religion and religious sects were not significantly correlated.

\section{DISCUSSION}

This study was conducted to determine the knowledge, practice and perceptions of contraception in a typical rural Nigerian community with a view to identifying culturally sensitive and appropriate interventions that will create an enabling atmosphere for effective contraceptive programming in Nigeria. We demonstrated in this study, that as much as $19.3 \%$ of the studied population had children without having being married or previously married. This in most instances is undoubtedly a result of an unplanned pregnancy that could have been prevented by effective contraceptive usage. ${ }^{11}$ Though the self-reporting contraceptive prevalence rate of $29.0 \%$ from this study is higher than the Nigeria national average, it is low when compared with the high level of contraceptive awareness. The high level of contraceptive awareness and low level of usage has also been previously established. ${ }^{12,13}$

Our study showed that majority of the respondents $(40.6 \%)$ got their information through friends or relatives. This result corroborates the findings of previous studies. ${ }^{11,14}$ However, information obtained through friends and relatives might be either incorrect or in- complete. But more of interest is that despite the high proportion $(49 \%)$ of the respondents who became aware from health personnel (nurses and doctors put together), it did not translate to increased contraceptive usage. This is at variance with reports from previous studies were health personnel contributed little to sources of awareness of contraception. ${ }^{15,16}$ This therefore raises the issue of the content of information passed to clients on contraception and contraceptive usage by the health personnel in this community. Their level of training in contraceptive services and how effectively they were able to convey relevant information to their clients was identified to be poor; hence one of the interventions that were undertaken was training and strengthening the capacity of the health personnel in this community following an early qualitative study. ${ }^{10}$

The study revealed that fewer than half of the study population was aware of emergency contraception and this is in keeping with earlier reports. ${ }^{15,16}$ However about four-fifth of these had correct information about emergency contraception, and this is contrary to the findings of an earlier report by Aziken et al. in which fewer than one-fifth of those aware of emergency contraception knew the correct timing for their use. ${ }^{16}$ In all, there is still a dearth of correct information on emergency contraception as above three-fifth of the respondents had no clue as to what emergency contraception is. This further underscores the fact that the sources from which members of this community get their information about contraception being not well informed or are characterized by ineffective communication of the appropriate information.

Another striking finding is the fact that despite the high awareness of contraception, over half of the respondents had no knowledge of which categories of persons that should actually use contraception. These is also inspite of the good knowledge of the commonly available contraceptive methods, and reassuringly, use of folk methods such as Menstrogen, quinine, traditional medication, gin/alcoholic beverages, gynaecosid and other methods as listed in the footnote of Table 3 ranked very low amongst the respondents. The implication of this is that with a good, comprehensive and well thought out information, education and communication programmes, the contraceptive uptake and usage is likely to be enhanced. When in particular, the leading reasons (fear of side effects, lack of knowledge, and lack of spousal consent) as to why the respondents were not using contraception are equally readily amenable to this form of educative programmes. Cultural and religious reasons that are likely to constitute deep seated primordial sentiments that would have acted as significant impediment to passing information easily was not of significance. 
In summary, this study revealed a high level of contraceptive awareness but with a low self-reporting prevalence rate and a poor knowledge of which categories of persons that should use contraception. The specific knowledge of emergency contraception was poor despite being aware of the common contraceptive commodities available. The factors associated with low and poor contraceptive usage were poor level of training in contraceptive services and ineffectively conveyance of relevant information to clients by health personnel, low literacy levels, extremes of reproductive age and extremes of parity. Others are fear of side effects, lack of knowledge, and lack of spousal consent. Effective educational and counselling interventions are likely to improve providers' and consumers' knowledge and subsequent uptake of contraceptive usage.

\section{ACKNOWLEDGEMENT}

We are extremely grateful to the Macarthur Foundation for providing the funds with which this study was undertaken. However, the findings and interpretations therein were in no way influenced by the Foundation. We would also like to thank Mr. Kingsley Iriferi who was instrumental to our linkages, smooth entrance into the community and indeed served as interpreter on a number of occasions.

\section{REFERENCES}

1. Abe E, Omo-Aghoja LO. Maternal mortality at the Central Hospital, Benin City Nigeria: A Ten Year Review. Afr J Reprod Health 2008; 12 [3]: 17-26.

2. Adewale IF. Trends in postabortal mortality and morbidity in Ibadan, Nigeria. Int. J. Gynecol Obstet $1992 ; 38$ (2): 115-8.

3. Sedgh G, Bankole A, Oye-Adeniran B, Adewole IF, Singh S, Hussain R. Unwanted pregnancy and associated factors among Nigerian women Int Fam Plann Perspect. 2006 Dec; 32(4): 175-84.

4. National Population Commission (NPC), Federal Republic of Nigeria and ORC Macro, Nigeria Demographic and Health Surveys 2003, Calverton, MD, USA: NPC and Macro. 2004, p.104.

5. Orji EO, Onwudiegwu U. Prevalence and determinants of contraceptive practice in a defined $\mathrm{Ni}$ gerian population. J. Obst Gynec 2002; 22(5): 540-543.
6. Ozumba BC, Obi SN, Ijioma NN. Knowledge, attitude and practice of modern contraception among single women in a rural community in southeast Nigeria. Journal of Obstetrics and Gynecology 2005; 25(3): 292-295.

7. Otoide VO, Oronsaye F, Okonofua FE. Why Nigerian adolescents seek abortion rather than contraception: evidence from focus group discussions. Int Fam Plan Pers 2001; 27(2): 77-81.

8. Maine D. Safe motherhood programmes. Options and Issues. 1991; Pp 37-40.

9. Shehu DJ. Community participation and mobilization in the prevention of maternal mortality in kebbi, North Western Nigeria. In: Safe motherhood initiatives: Critical Issues, ( $1^{\text {st }}$ edition). Berer $M$ and Sundari TK (eds). Ravindian.

10. Omo-Aghoja L O, Omo-Aghoja VW, Okonofua FE, Aghedo O, Umueri C, Otayohwo R, FeyiWaboso p, Esume CO. Perceptions and attitudes of a rural community to abortion in the Nigerdelta region of Nigeria. Nigeria J Clin Prac (in press).

11. Adewale IF, Oye-Adeniran BA, Iwere N, Oladokun A, Gbadegesin A et al. Contraceptive usage among abortion seekers in Nigeria. West Afr J Med 2002; 21: 112-114.

12. Okonofua FE, Odimegwu C, Ajabor H, Daru PH, Johnson A. Assessing the prevalence an determinants of unwanted pregnancy and induced abortion in Nigeria. Stud Fam Plann 1999; 30: 67-77.

13. Obisesan KA, Adeyemo AA, Fakokunde FA. Awareness and use of family planning methods among married women in Nigeria. East Afr Med J 1998; 75: 135-138.

14. Boniface A Oye-Adeniran, Isaac F. Adewale, Augustine V Umoh, Adesina Oladokun, Abidoye Gbadegesin, Kofo A. Odeyemi et al. Sources of Contraceptive Commodities for Users in Nigeria. PLoS Med 2005; 2 (11): e306].

15. Aziken ME, Okonta PI, Ande ABA. Knowledge and perception of Emergency Contraception Among Female Nigerian Undergraduates. International Family Planning Perspectives 2003; 29 (2): 84-87

16. Ebuehi $\mathrm{OM}$ et al. Knowledge and practice of emergency contraception among female undergraduates of the University of Lagos. East Afr Med J 2006; 83 (3): 20-25 